\title{
Substance abuse: a national survey of Canadian residency program directors and site chiefs at university-affiliated anesthesia departments
}

\section{L'abus de substances: un questionnaire national auprès des directeurs de programmes de résidence en anesthésie au Canada et des chefs de site des départements d'anesthésie affiliés à des universités}

\author{
Sherif Boulis, MD • P. Kristina Khanduja, MBChB - Kristi Downey, MSc • \\ Zeev Friedman, MD
}

Received: 30 September 2014/Accepted: 14 May 2015/Published online: 22 May 2015

(C) Canadian Anesthesiologists' Society 2015

\begin{abstract}
Purpose The abuse of substances available to anesthesiologists in their workspace is a potentially lethal occupational hazard. Our primary objective was to define the prevalence of substance abuse cases among Canadian anesthesiologists at university-affiliated hospitals. Our secondary aim was to describe the current management of confirmed cases, rehabilitation procedures being offered, and preventative strategies being employed. Methods We conducted a cross-sectional electronic survey of all Canadian anesthesia residency program directors and site chiefs at university-affiliated hospitals. Data analysis was performed using descriptive statistics. Results The survey response rate was 54\% (53/98). Substance abuse was reported as $1.6 \%$ for residents and $0.3 \%$ for clinical fellows over a ten-year period ending in June 2014. Fentanyl was abused in nine of 24 reported
\end{abstract}

\begin{abstract}
Author contributions Sherif Boulis, Kristi Downey, and Zeev Friedman designed the study and contributed to the data collection. $P$. Kristina Khanduja contributed to the analysis and interpretation of data and wrote and revised the manuscript. Kristi Downey and Zeev Friedman reviewed and revised the manuscript.
\end{abstract}

Electronic supplementary material The online version of this article (doi:10.1007/s12630-015-0404-1) contains supplementary material, which is available to authorized users.

S. Boulis, MD · P. K. Khanduja, MBChB ( $₫)$.

K. Downey, MSc · Z. Friedman, MD

Department of Anesthesia and Pain Management, Mount Sinai Hospital, University of Toronto, 600 University Avenue, Room 19-104, Toronto, ON M5G 1X5, Canada

e-mail: kkhanduja@mtsinai.on.ca cases. At present, one of 22 respondents (4.5\%) reported a formal education program on substance abuse for faculty members, and $72 \%$ described mandatory education for residents. The majority of participants did not perceive substance abuse as a growing problem. Seventy-one percent of respondents indicated that methods for controlled-drug handling had changed in the previous ten years; however, $66 \%$ did not think that the incidence of controlled substance abuse could be decreased further by more stringent measures. Only $21 \%$ of respondents supported the introduction of random urine drug testing.

Conclusion The prevalence of substance abuse among Canadian anesthesiologists and the substances abused appear comparable with data from the United States, with residents being the group most often affected. Early recognition and treatment of chemically dependent anesthesiologists remain imperfect.

\section{Résumé}

Objectif L'abus des substances à disposition des anesthésiologistes sur leur lieu de travail est un risque professionnel potentiellement fatal. Notre objectif principal était de définir la prévalence des cas d'abus parmi les anesthésiologistes canadiens dans les hôpitaux affiliés à des universités. Notre objectif secondaire était de décrire la prise en charge actuelle des cas d'abus confirmés, les procédures de réhabilitation proposées et les stratégies de prévention employées.

Méthode Nous avons réalisé une enquête électronique ponctuelle auprès de tous les directeurs de programmes de 
résidence en anesthésie et de tous les chefs de site dans les hôpitaux affiliés à des universités. L'analyse des données a été réalisée à l'aide de statistiques descriptives.

Résultats Le taux de réponse au sondage était de $54 \%$ (53/98). Des cas d'abus de substances ont été rapportés à hauteur de 1,6\% chez les résidents et de 0,3\% chez les assistants de clinique (fellows) au cours d'une période de dix ans prenant fin en juin 2014. Le fentanyl était l'agent de choix dans neuf des 24 cas d'abus rapportés. À l'heure actuelle, un seul parmi les 22 répondants $(4,5 \%)$ a fait état d'un programme de formation formel sur l'abus de substances pour les membres des départements d'anesthésie, et $72 \%$ ont décrit une formation obligatoire pour les résidents. La majorité des participants ne considèrent pas l'abus de substances comme un problème croissant. Soixante-et-onze pour cent des répondants ont indiqué que les méthodes de surveillance des médicaments contrôlés avaient changé au cours des dix dernières années; toutefois, $66 \%$ ne pensaient pas que l'incidence d'abus de médicaments contrôlés pouvait être réduite en mettant en place des mesures plus rigoureuses. Seuls $21 \%$ des répondants étaient en faveur de l'introduction de tests d'urine aléatoires.

Conclusion La prévalence de l'abus de substances parmi les anesthésiologistes canadiens et les substances de leur abus semblent se comparer aux données dont nous disposons pour les États-Unis, et les résidents constituent le groupe de personnes le plus touché. Le dépistage et le traitement précoces des anesthésiologistes dépendants de substances chimiques demeurent imparfaits.

Substance use disorders, including use of alcohol and cannabis, have been estimated to affect approximately $22 \%$ of Canadians over a lifetime. ${ }^{1}$ Substance abuse by physicians not only poses severe risks for the affected individual but also endangers patient care and jeopardizes the public's trust in healthcare providers. Previous literature suggests that up to $12 \%$ of physicians will suffer from substance abuse during their career., ${ }^{2,3}$

Abuse patterns, however, are not distributed evenly across specialties. Surveys conducted from the early 1980s2008 suggest that anesthesiologists may be at highest risk, particularly during the earlier stages of their career. ${ }^{4-9}$ Collins' study of 111 United States anesthesiology training programs in 2005 reported that $80 \%$ of programs had experience with trainee impairment, primarily opioid abuse. Nineteen percent of programs reported at least one death due to overdose or suicide during 1991-2001. ${ }^{10}$ Substance abuse amongst anesthesiology residents has been estimated to be as high as $1.6 \% .^{11}$ Ease of access to opioids, benzodiazepines, and other substances may contribute to the apparent overrepresentation of anesthesiologists with substance abuse problems. ${ }^{12,13}$

Considerable efforts have gone towards reducing abuse of controlled substances within the specialty. These have relied mainly on heightened awareness to recognize the early symptoms and signs of substance abuse, education (e.g., lectures by recovering physicians), and strict substance control (e.g., daily accounting, establishing operating room pharmacies) in order to detect and discourage substance abuse. ${ }^{14-16}$

Our primary goal was to define the prevalence of known substance-abuse cases amongst Canadian anesthesiology trainees and attending physicians at university-affiliated centres over the last ten years through a nationwide crosssectional survey. We included alcohol in our survey as well as those substances accessible to anesthesiologists in their work environment. A secondary aim was to describe the current management of confirmed cases and the rehabilitation procedures being offered. We further aimed to explore the preventative strategies currently employed, including the number of hours of formal education, policies regarding regulated use and disposal of controlled substances, as well as the use of random urine testing.

\section{Methods}

Following local Research Ethics Board approval (Mount Sinai Hospital, Toronto, Ontario; June 2013), an electronic survey was sent via e-mail to all 17 Canadian universityaffiliated departments of anesthesia. We chose to sample university-affiliated departments of anesthesia for two reasons: (1) to assess the scope of substance abuse across all levels of training and practice; and (2) there was no single registry of contact information for non-university departments or anesthesiologists working outside the hospital setting. Databases of the Association of Canadian University Departments of Anesthesiology (ACUDA) and the Royal College of Physicians and Surgeons of Canada were used as the sampling frame to locate and contact eligible program directors and site chiefs.

Our survey was designed and validated in line with previously published recommendations on selfadministered surveys for clinicians. ${ }^{17}$ Although we appreciate that our population of interest may be at risk of developing an addiction to a variety of substances, we focused on those substances that are accessible to anesthesiologists in the workplace. We decided to include alcohol abuse in our survey as it was previously reported as the substance most commonly abused by physicians regardless of specialty. ${ }^{2}$ 
Following a detailed review of previously published literature, the authors iteratively generated items for inclusion and concurrently removed items deemed redundant until consensus was reached.

Questions were designed to elicit a nominal response (Electronic Supplementary Material - Appendix: copy of survey). In addition, respondents had the option to add free-text responses and comments to enhance our data collection. Lastly, we piloted our survey internally to gain feedback on time to completion, flow, and clarity of questions.

Recipients were asked to provide the names of their predecessors in the last ten years, and potential participants identified by this means were also invited to complete the survey. Since there is currently no formal database or register to account for all Canadian academic (i.e., university-affiliated) anesthesia departments, we utilized a snowball sampling technique. Individual program directors were also requested to forward either contact information for their administrative staff and/or a list of universityaffiliated academic teaching hospitals and their respective site chiefs. A modified survey was forwarded to explore patterns of substance abuse amongst Canadian anesthesiology fellows and staff (Appendix; available as Electronic Supplementary Material).

The first set of e-mails containing links to the survey was distributed in March 2014. A reminder e-mail was sent to departments that did not respond to the initial survey. Our data collection was completed by June 2014. The online survey was sent to prospective participants via FluidSurveys $^{\mathrm{TM}}$ (Ottawa, ON, Canada). Survey responses were exported to Microsoft Excel (Redmond, WA, USA) for subsequent analysis.

Data analysis was performed using descriptive statistics. We estimated the denominator for the number of Canadian anesthesiology residents, clinical fellows and attending staff based on our survey data. In order to prevent duplicate reporting of known cases of substance abuse, program directors were requested to report only cases involving residents, and site chiefs were requested to report only cases involving fellows and faculty. We then hand scored cases in order to identify and exclude duplications based on their variables (respondent, institute, designation, substance being abused, etc.).

\section{Results}

Of 98 surveys distributed to Canadian anesthesiology program directors and site chiefs, $53(54 \%)$ were returned, five of which were returned unanswered and excluded from data analysis (Figure). Nine respondents were acting as program directors, 34 were site chiefs, and five were

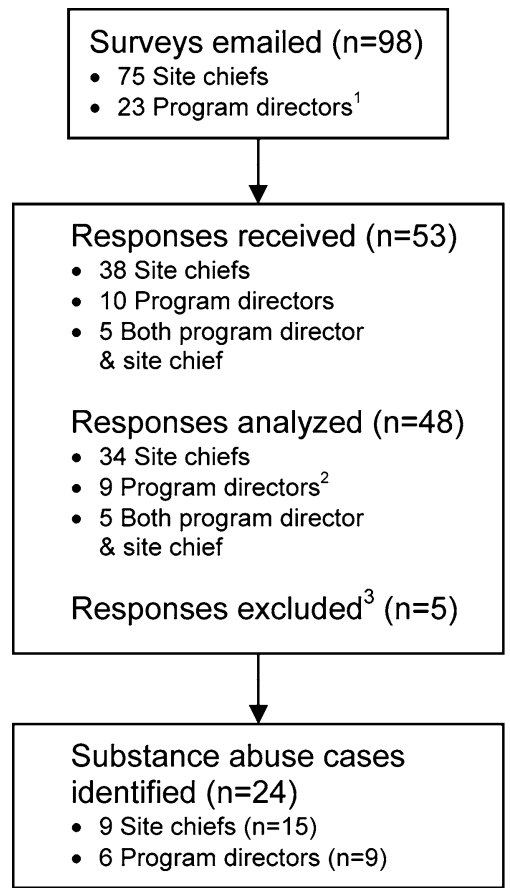

Figure Survey sample and response flow ${ }^{1}$ There are presently 17 Association of Canadian University Departments of Anesthesiology (ACUDA) programs; six programs were surveyed twice due to a recent change in program director. ${ }^{2}$ Representing 14 of 17 ACUDA programs. ${ }^{3}$ Surveys returned unanswered

functioning in both roles. In total, 75 institutions were invited to participate in the survey. At the time of survey completion, responding program directors estimated the number of residents as 626 over the previous ten-year period with site chiefs having reported the number of anesthesiology fellows as 1,530. Of importance, these figures represent the cumulative number of individuals employed at resident and clinical fellow grade at academic centres over the preceding ten-year time period rather than the number of respective positions. In 2014, there were 953 attending anesthesiologists practicing at academic centres in Canada.

The first part of the survey concentrated on the reported incidents. We surveyed the number of cases, choice of substance, means of detection, and subsequent management and outcome (Table 1). There were 24 reported cases of substance abuse consisting of ten resident physicians, five clinical fellows, and nine attending staff. It is noteworthy that seven respondents indicated their uncertainty as to whether there were any cases of substance abuse at their institution in the preceding ten years. In five cases, the individuals were reported to abuse more than one drug. Opioids were the substance of choice in the majority of cases (Table 1), and fentanyl was the controlled opioid most often abused $(n=9)$. Using the reported population of residents and clinical fellows as the 
Table 1 Summary of substances abused

\begin{tabular}{|c|c|c|c|c|}
\hline Substance(s) abused & $\begin{array}{l}\text { Resident } \\
(n=10)\end{array}$ & $\begin{array}{l}\text { Fellow } \\
(n=5)\end{array}$ & $\begin{array}{l}\text { Faculty } \\
(n=9)\end{array}$ & $\begin{array}{l}\text { Total number } \\
\text { of cases }\end{array}$ \\
\hline $\begin{array}{l}\text { Opioids (fentanyl, sufentanyl, oxycodone/oxycontin, remifentanil, } \\
\text { meperidine)* }\end{array}$ & $6(60)$ & $4(80)$ & $5(56)$ & 15 \\
\hline Alcohol & $1(10)$ & $1(20)$ & $1(11)$ & 3 \\
\hline Propofol & $0(0)$ & $0(0)$ & $1(11)$ & 1 \\
\hline Ketamine & $1(10)$ & $0(0)$ & $0(0)$ & 1 \\
\hline Unknown & $1(10)$ & $0(0)$ & $0(0)$ & 1 \\
\hline Other (multiple substances) ${ }^{\dagger}$ & $1(10)$ & $0(0)$ & $2(22)$ & 3 \\
\hline
\end{tabular}

Data is presented as count $(\%)$

*Two cases involved the abuse of fentanyl and sufentanyl; one case involved hydromorphone and oxycodone/oxycontin

${ }^{\dagger}$ One case: opioid and benzodiazepines; one case: opioid and propofol; one case: alcohol and inhalational anesthetics

denominator yields the following rates of known substance abuse, $1.6 \%$ for residents and $0.3 \%$ for clinical fellows. As we were unable to determine an accurate number for the attending anesthesiologist practicing at Canadian, we were unable to determine a true prevalence rate and instead only report the actual numbers with substance abuse.

Substance abuse was first suspected on the basis of behavioural changes in ten cases $(41.7 \%)$, followed by witnessed substance abuse in nine cases (37.5\%), and voluntary admission in six cases $(25.0 \%)$. In four cases $(16.7 \%)$, a change in the pattern of controlled substance requests/usage was observed. In three cases, substance abuse was suspected only after a related patient death. In 21 cases $(77.2 \%)$, confirmation of controlled substance abuse occurred after voluntary admission. Of importance, none of the cases underwent drug testing, neither as part of random testing nor for confirmation of suspected substance abuse. Table 2 summarizes the outcomes for the affected individuals after confirmed controlled-substance abuse.

The second part of the survey elicited departmental policies for rehabilitation and prevention of substance abuse in the workplace. In addition, we sought the perceptions and attitudes of the program directors and site chiefs towards substance abuse amongst anesthesiologists. Over $60 \%$ of respondents indicated that faculty and residents (23 of 37 responses and 9 of 15 responses, respectively) would be offered re-employment after successful completion of a drug rehabilitation program. Less than $3 \%$ of respondents stated that departments would contribute towards the cost of treatment for fellows and faculty if not covered by the individual's heath benefit program ( 1 of 36 responses and 1 of 37 responses, respectively). In the case of resident physicians, $13 \%$ (2 of 15 responses) would contribute towards cost. With respect to financial support during substance abuse treatment, respondents indicated that $33 \%$
(5 of 15 responses) of departments would offer a salary to residents. For faculty and fellows, however, only 5.4\% (2 of 37 responses) and $5.6 \%$ ( 2 of 36 responses) of respondents, respectively, reported a departmental policy for ongoing salary payments.

Based on our survey responses, less than $10 \%$ of departments insist on formal education regarding substance abuse for faculty and fellows ( 1 of 22 responses and 2 of 22 responses, respectively). Seventy-seven percent of respondents (10 of 13 responses) specified mandatory education for residents of up to $2.5 \mathrm{hr}$ per year of training.

Twelve percent of respondents (5 of 43 responses) perceive substance abuse amongst anesthesiologists in academic programs as a growing problem and suspect a rise in its incidence. Seventy-five percent of respondents (33 of 44 responses) indicated that they do not have a substance-abuse committee or a designated contact person within their departments. Only $16 \%$ (7 of 45 responses) reported an increase in the hours of formal education dedicated towards awareness and prevention of substance abuse.

Approximately half of respondents ( 24 of 45 responses), however, do not consider more extensive education on substance abuse as an effective means of decreasing its incidence. Furthermore, $66 \%$ of respondents (29 of 44 responses) do not think increased accountability with enhanced measures for dispensing and disposal of controlled substances will diminish the scope of the problem. When surveyed on random drug testing, 21\% (9 of 43 responses) of respondents argued in favour, while the majority (79\%) of respondents (34 of 43 responses) did not perceive a role for such a practice.

Of the cases of known substance abuse, 18 anesthesiologists (75\%) re-entered the workplace following treatment. Amongst these cases, 12 returned to the same position, three returned to anesthesia positions 
Table 2 Outcomes in cases of confirmed substance abuse

\begin{tabular}{lr}
\hline Outcome & $n=24$ \\
\hline Treatment & $19(79.2)$ \\
Relapse & $4(16.7)$ \\
Return to same residency or faculty position & $12(50.0)$ \\
Return to anesthesia practice elsewhere & $3(12.5)$ \\
Return to a different field of medicine & $3(12.5)$ \\
Death related to use of controlled substances & $5(20.8)$ \\
Currently drug free & $9(37.5)$ \\
Uncertain & $4(16.7)$ \\
\hline
\end{tabular}

Data is presented as count (\%) of 24 cases reported

elsewhere, and three returned to a different field of medicine. In addition, four anesthesiologists suffered a relapse; there were five cases of subsequent death related to substance abuse.

The third and final part of the survey assessed accountability measures for controlled substances. Table 3 summarizes current practices with regard to dispensing, recording administration, and disposal of controlled substances. Seventy-one percent of respondents (34 of 44 responses) asserted that these methods had

Table 3 Practices for accountability, dispensing, and disposal of controlled substances

\begin{tabular}{|c|c|c|}
\hline \multicolumn{2}{|l|}{ Method } & \multirow{2}{*}{$\begin{array}{l}n=44 \\
42(95.5)\end{array}$} \\
\hline Accountability* & Pharmacy record & \\
\hline & Pharmacy summation & $37(84.1)$ \\
\hline & $\begin{array}{l}\text { Pharmacy comparison of controlled } \\
\text { substance dispensed and returned }\end{array}$ & 17 (38.6) \\
\hline & $\begin{array}{l}\text { Required return of residual controlled } \\
\text { substance with random chemical } \\
\text { analysis }\end{array}$ & $0(0)$ \\
\hline & $\begin{array}{l}\text { Random tracking of pattern of controlled } \\
\text { substance dispensing and usage }\end{array}$ & $5(11.4)$ \\
\hline & $\begin{array}{l}\text { Random urine testing of anesthesia } \\
\text { providers }\end{array}$ & $0(0)$ \\
\hline \multirow{5}{*}{$\begin{array}{l}\text { Drug } \\
\text { Dispensing }\end{array}$} & Dispensing machines & $23(52.3)$ \\
\hline & Locked box & $11(25.0)$ \\
\hline & Traditional nurse dispensing & $6(13.6)$ \\
\hline & Satellite pharmacy & $3(6.8)$ \\
\hline & No response provided & $1(2.3)$ \\
\hline \multirow[t]{3}{*}{ Drug Disposal } & $\begin{array}{l}\text { Anesthesia provider wastes excess } \\
\text { without witness }\end{array}$ & $34(77.2)$ \\
\hline & $\begin{array}{l}\text { Anesthesia provider wastes excess with } \\
\text { witness }\end{array}$ & $8(18.2)$ \\
\hline & $\begin{array}{l}\text { Anesthesia provider returns excess to } \\
\text { pharmacy }\end{array}$ & $2(4.5)$ \\
\hline
\end{tabular}

Data presented as count (\%) of 44 survey responses

* Respondents were able to select multiple options for accountability changed in the previous ten years. According to $95.5 \%$ of respondents, handwritten pharmacy records remain the most commonly reported means of accounting for controlled substance administration (42 of 44 responses). The majority $(53.5 \%)$ of respondents in our survey utilize automated dispensing machines (23 of 43 responses). According to $77.2 \%$ of respondents, in most instances, the anesthesia provider wastes unused (residual) portions of controlled substances without a witness (34 of 44 responses).

\section{Discussion}

Our study examined the prevalence of substance abuse amongst anesthesiologists at academic centres in Canada over a ten-year period spanning 2004-2014. The focus of our study centred on alcohol and the use of controlled substances accessible within the operating room setting. The rate of reported substance abuse amongst anesthesiologists was $1.6 \%$ for residents and $0.3 \%$ for clinical fellows. In a previous study by Booth et al. in the United States, the rates of substance abuse during a sevenyear period starting in 1990 were $1.6 \%$ for residents and $1 \%$ for staff at academic medical centres. ${ }^{11}$ Although these figures may appear comparable, our relatively low survey response rate limits our ability to comment categorically on the prevalence of substance abuse amongst anesthesiologists in Canada.

Opioids remain the substance most commonly abused by anesthesiologists in Canada. Our findings are consistent with previous literature on substance abuse across the medical specialties; different groups of physicians tend to suffer from addiction to different agents. Whereas alcohol has steadily remained the agent of choice for physicians as a whole, anesthesiologists appear to have a predilection towards intravenous opioid abuse. ${ }^{18}$ Studies pre-dating the 1980s identified meperidine, a synthetic opioid, to be the most frequently abused controlled substance, followed closely by benzodiazepines and barbiturates. ${ }^{19}$ In line with our results, fentanyl has since superseded meperidine as the opioid most often implicated in reported cases of chemical dependence. , $^{3,10,20}$

There were two cases of propofol abuse reported in our results. Although propofol may not appear as a traditional drug of abuse, a survey conducted amongst academic anesthesiology programs in the United States showed a fivefold rise in the rate of its abuse from 1995-2005; furthermore, $28 \%$ of these cases were detected only following death due to overdose, indicating a largely unrecognized problem. ${ }^{21}$ We also found an alarming percentage of cases of substance abuse $(12.5 \%)$ that were unrecognized until a fatality occurred. 
Our figures highlight the ongoing challenge of rehabilitating physicians with known previous substance abuse. Although abstinence rates amongst physicians following successful treatment are high and akin to outcomes in similarly demanding professions, such as aviation, anesthesiologists form a unique subset of the physician population. ${ }^{22}$ Previous studies have shown that anesthesiologists who have suffered from addiction to substances accessible within the operating room environment (e.g., opioids, propofol, and volatile agents) have a higher relapse rate with an increased risk of morbidity and mortality when compared with physicians in other specialties. ${ }^{23}$ Perhaps not surprisingly, this has led to diverse opinions with regard to the appropriateness of reentry into clinical anesthesiology practice. In their editorial in 2009, Berge et al. take a strong stance towards a "one strike you're out" policy, whereby recovering anesthesiologists are discouraged from re-entry into anesthesiology and directed towards lower-risk occupational fields within medicine or a different occupation altogether. ${ }^{24}$ Others advocate for a controlled and graded re-entry into clinical practice under the supervision of a treatment team. ${ }^{22}$

Our results indicate differences in policies on financial support for residents and faculty during treatment for substance abuse. Unlike residents, staff at academic centres frequently belong to hospital-based practice plans (with few receiving direct salary from Universities or hospitals themselves) with reliance on fee-for-service billing and income sharing within their partnerships. We suspect that most partnerships would not provide financial support in times of disability and, instead, would encourage individual staff to purchase disability insurance suited to their own personal financial situations. This may in turn explain the low rate of contribution towards treatment/ disability support during rehabilitation for faculty.

Our results indicate that residents form the primary target of mandatory educational training on substance abuse. Since the early 1990s, concerted efforts have been made in academic programs in the United States to implement initiatives that raise awareness of substance abuse in anesthesiology. ${ }^{11}$ Although such efforts may serve as a strategy towards earlier detection of affected individuals, it is unclear whether education can truly have an impact on the prevention and prevalence of substance abuse. ${ }^{11,25}$ The absence of compelling supporting evidence may account for our respondents' lack of conviction of the benefit in further hours of mandatory training. A noteworthy counter argument raised by Booth et al. takes into account that educational interventions will invariably fail if directed solely at residents. ${ }^{11}$ Our results show that re-exposure to substance abuse education after residency is rare; moreover, staff (and their families) are not included in educational programs.

Another instrument in the prevention of substance abuse is control of the removal of substances from the operating room. Practices with regard to dispensing, documentation, and disposal appear to have tightened across most Canadian academic centres over the previous decade. Over $50 \%$ of respondents utilize dispensing machines. Our findings reflect an increasing trend away from more traditional methods, such as dispensing by nursing staff, observed in previous surveys. ${ }^{11,26}$ Nevertheless, less than $12 \%$ of respondents currently perform random tracking of patterns of controlled substance dispensing/usage for a given anesthesia provider. The majority of respondents indicated that further measures would be of little benefit, likely coinciding with a belief that the incidence of substance abuse in anesthesiology is not increasing.

Random urine testing has not been implemented in any of the centres that took part in our survey. Moreover, the majority of respondents indicated that they would not advocate for such a practice at their institution. We can only speculate as to why respondents were almost unanimously opposed to random urine testing of anesthesiologists in the workplace. Contributory factors may include problems such as the reliability of assays, the risk of false positive results, curtailing of individual freedom, and cost. $^{25}$ Despite these potential disadvantages, the concept appears to be less contentious in the United States where most program directors and site chiefs support its introduction. ${ }^{11}$

Several professions whose members are responsible for the lives of others (e.g., aviation and transportation industries) have experienced problems with substance abuse. $^{27}$ Some airline companies, for example, are required by law to conduct random urine testing in an attempt to reduce the risk of substance abuse. ${ }^{28}$ Illicit drug use appears to have decreased significantly after random urine testing was initiated in the United States military in the early 1990s. ${ }^{29,30}$

The Department of Anesthesia at Massachusetts General Hospital initiated pre- and post-placement random urine testing of all anesthesia residents not only to detect existing substance abuse but also to deter from ongoing substance abuse. ${ }^{14}$ The annual cost of random urine testing has been estimated at approximately $\$ 50,000 .^{14}$ The total cost of returning a physician to unrestricted medical practice, on the other hand, is likely in excess of $\$ 100,000 .^{14}$ Thus, deterring a single physician from illicit drug use could be considered cost effective.

We are aware that there are a number of limitations to our study. We specifically sought to examine cases of confirmed substance abuse amongst all anesthesiologists at academic institutions in Canada through survey 
methodology and retrospective reporting. Despite our efforts, our study did have a relatively low response rate, which limits our ability to obtain an accurate assessment of the problem. Further factors may have led to underreporting. For instance, the early symptoms and signs of substance addiction may be subtle and are often unrecognized until the later stages, ${ }^{3}$ thereby hindering accurate detection. By including only confirmed cases of substance abuse, we have almost certainly underestimated the prevalence. The number of undetected cases of substance abuse and the proportion that end in a tragic outcome prior to recognition remain largely unknown. In addition, our survey does not address the effects of substance abuse beyond the affected individual, such as the potential of adverse patient outcomes and harm.

A ten-year period is longer than the average tenure of a program director and/or site chief, which may have also led to underreporting. The latter, however, is ameliorated by the fact that, although infrequent, cases of substance abuse are memorable with resultant discussions when the role of program director or site chief was assumed.

We limited our data collection to university-affiliated centres in Canada, thereby excluding anesthesiologists at non-university-affiliated community hospitals. Furthermore, we were unable to estimate a true denominator for the number of staff practicing at Canadian academic centres over the previous decade. As a result, we were unable to report the estimated prevalence of substance abuse amongst this population and reported only the number of cases.

We consider our survey a modest start at trying to define the scope of a longstanding problem within our specialty. Strategies that enhance physician survey response rates must be considered when planning future survey-based studies. Such approaches may include incentive-based interventions (both monetary and non-monetary) or designbased interventions (e.g., offering an alternative to electronic survey completion, including postal questionnaires with pre-paid return envelopes or telephone survey) and up to three follow-up reminders (sent via either e-mail or regular mail). ${ }^{17,31,32}$ In the meantime, we can simply echo the sentiment voiced by previous investigators in the United States, that a mandatory anonymous reporting system linked to a national database may be an appropriate next step in delineating the extent of substance abuse in our specialty. Only by such means can we truly establish patterns of change and examine the impact of educational and other preventative strategies. We urge ACUDA, in particular, to take action on the matter of substance abuse. Although not limited to trainees, substance abuse will often manifest in the earlier years of anesthesiology training, ${ }^{20}$ thereby making the recognition and treatment of vulnerable individuals a matter of priority.

\section{Conclusion}

Despite efforts to tighten practices around accountability and disposal of controlled drugs in the operating room, opioids remain the substance most often abused by anesthesiologists at Canadian university-affiliated centres. In three cases, substance abuse was identified only following a related death. These incidents highlight that early recognition and treatment of chemically dependent anesthesiologists remains imperfect.

At present, there is much variability in policy on education, the response to substance abuse once detected, and accountability for recording the use and wastage of controlled substances in the operating room.

Acknowledgements The authors gratefully acknowledge all program directors and site chiefs who took the time to respond to the survey.

Conflicts of interest None declared.

\section{References}

1. Pearson C, Janz T, Ali J. Mental and substance use disorders in Canada. Statistics Canada, Health Statistics Division 2013. Available from URL: http://www.statcan.gc.ca/pub/82-624-x/ 2013001/article/11855-eng.pdf (accessed March 2015).

2. Baldisseri MR. Impaired healthcare professional. Crit Care Med 2007; 35: S106-16.

3. Berge KH, Seppala MD, Schipper AM. Chemical dependency and the physician. Mayo Clin Proc 2009; 84: 625-31.

4. McLellan AT, Skipper GS, Campbell M, DuPont RL. Five year outcomes in a cohort study of physicians treated for substance use disorders in the United States. BMJ 2008; 337: a2038.

5. Ward $C F$. Physicians with opioid dependence. JAMA 2005; 293: 294.

6. Ward CF, Ward GC, Saidman LJ. Drug abuse in anesthesia training programs. A survey: 1970 through 1980. JAMA 1983; 1983(250): 922-5.

7. Ward CF. Substance abuse. Now, and for some time to come. Anesthesiology 1992; 77: 619-22.

8. Alexander BH, Checkoway H, Nagahama SI, Domino KB. Causespecific mortality risks of anesthesiologists. Anesthesiology 2000; 93: 922-30.

9. Talbott GD, Gallegos KV, Wilson PO, Porter TL. The Medical Association of Georgia's Impaired Physicians Program. Review of the first 1000 physicians: analysis of specialty. JAMA 1987; 257: $2927-30$

10. Collins GB, McAllister MS, Jensen M, Gooden TA. Chemical dependency treatment outcomes of residents in anesthesiology: results of a survey. Anesth Analg 2005; 101: 1457-62.

11. Booth JV, Grossman D, Moore J, et al. Substance abuse among physicians: a survey of academic anesthesiology programs. Anesth Analg 2002; 95: 1024-30.

12. Lutsky I, Hopwood M, Abram SE, Jacobson GR, Haddox JD, Kampine JP. Psychoactive substance use among American anesthesiologists: a 30-year retrospective study. Can J Anaesth 1993; 40: 915-21. 
13. Lecky JH, Aukburg SJ, Conahan TJ 3rd, et al. A departmental policy addressing chemical substance abuse. Anesthesiology 1986; 65: 414-7.

14. Fitzsimons $M G$, Baker KH, Lowenstein E, Zapol WM. Random drug testing to reduce the incidence of addiction in anesthesia residents: preliminary results from one program. Anesth Analg 2008; 107: 630-5.

15. Brewster JM. Prevalence of alcohol and other drug problems among physicians. JAMA 1986; 255: 1913-20.

16. O'Kane Martin K, Mazmanian PE. Physician substance abuse: Prevention through reeducation. J Contin Educ Health Prof 1990; 10: 35-46.

17. Burns KE, Duffett $M$, Kho ME, ACCADEMY Group, et al. A guide for the design and conduct of self-administered surveys of clinicians. CMAJ 2008; 179: 245-52.

18. Gallegos $K V$, Browne $C H$, Veit $F W$, Talbott GD. Addiction in anesthesiologists: drug access and patterns of substance abuse. QRB Qual Rev Bull 1988; 14: 116-22.

19. Hughes PH, Storr CL, Brandenburg NA, Baldwin DC Jr, Anthony $J C$, Sheehan $D V$. Physician substance use by medical specialty. J Addict Dis 1999; 18: 23-37.

20. Tetzlaff JE. Drug diversion, chemical dependence, and anesthesiology. Adv Anesth 2011; 29: 113-27.

21. Wischmeyer PE, Johnson BR, Wilson JE, et al. A survey of propofol abuse in academic anesthesia programs. Anesth Analg 2007; 105: 1066-71.

22. Oreskovich MR, Caldeiro RM. Anesthesiologists recovering from chemical dependency: can they safely return to the operating room? Mayo Clin Proc 2009; 84: 576-80.

23. Menk EJ, Baumgarten RK, Kingsley CP, Culling RD, Middaugh $R$. Success of reentry into anesthesiology training programs by residents with a history of substance abuse. JAMA 1990; 263: 3060-2.

24. Berge KH, Seppala MD, Lanier WL. The anesthesiology community's approach to opioid- and anesthetic-abusing personnel: time to change course. Anesthesiology 2008; 109: 762-4.

25. Bryson EO, Silverstein JH. Addiction and substance abuse in anesthesiology. Anesthesiology 2008; 109: 905-17.

26. Klein RL, Stevens WC, Kingston HG. Controlled substance dispensing and accountability in United States anesthesiology residency programs. Anesthesiology 1992; 77: 806-11.

27. Botch SR, Johnson RD. Civilian Aviation fatalities involving pilot ethanol and a previous record of substance abuse. Aviat Space Environ Med 2009; 80: 841-4.

28. Gibson P. Australian aviation industry prepares for substance abuse testing. Airport Security Report 2006; 13: 2.

29. Bray RM, Marsden ME, Rachal JV, Pedersen MR. Drug and alcohol use in the military workplace: findings from the 1988 worldwide survey. NIDA Res Monogr 1990; 100: 25-43.

30. Bray RM, Hourani $L L$. Substance use trends among active duty military personnel: findings from the United States Department of Defense Health Related Behavior Surveys, 1980-2005. Addiction 2007; 102: 1092-101.

31. Nicholls $K$, Chapman K, Shaw T, et al. Enhancing response rates in physician surveys: the limited utility of electronic options. Health Serv Res 2011; 46: 1675-82.

32. VanGeest JB, Johnson TP, Welch VL. Methodologies for improving response rates in surveys of physicians: a systematic review. Eval Health Prof 2007; 30: 303-21. 